\title{
TNF $\alpha$ Regulates SIRT1 Cleavage during Ocular Autoimmune Disease
}

Peter J. Gardner, ${ }^{*}$ Samia Yazid, ${ }^{*}$ Colin J. Chu, ${ }^{* \dagger}$ David A. Copland, ${ }^{\dagger \dagger}$ Peter Adamson, ${ }^{\S}$ Andrew D. Dick, ${ }^{* \dagger+ब}$ and Virginia L. Calder ${ }^{\ddagger}$

From the Departments of Genetics* and Ocular Biology and Therapeutics, "University College London Institute of Ophthalmology, London; the Academic Unit of Ophthalmology, ${ }^{\dagger}$ School of Clinical Sciences, and the School of Cellular and Molecular Medicine, ${ }^{\mathbb{}}$ University of Bristol, Bristol; the National Institute for Health Research Biomedical Research Centre at Moorfields Eye Hospital and University College London Institute of Ophthalmology, ${ }^{\ddagger}$ London; and the Ophthiris Discovery Performance Unit, ${ }^{\S}$ GlaxoSmithKline Ophthalmology, Stevenage, United Kingdom

Accepted for publication January 7, 2015.

Address correspondence to Peter J. Gardner, Ph.D., Department of Genetics, UCL Institute of Ophthalmology, 11-43 Bath St, London EC1V 9EL, United Kingdom. E-mail: p.gardner@ucl.ac.uk.

\begin{abstract}
Elevated tumor necrosis factor (TNF) $\alpha$ levels are associated with chronic autoimmune diseases in which effects of TNF $\alpha$ on immune cells are multiple and complex. Analysis of uveitis in mice exhibiting severe autoimmune inflammation, resulting in a destructive subtotal loss of photoreceptors, revealed the presence of high plasma levels of TNF $\alpha$ and a significant population of $\mathrm{CD} 4^{+} \mathrm{TNF} \alpha^{+}$cells in the periphery and the eye at peak disease (TNF $\left.\alpha^{\text {hi }}\right)$. We have shown previously by pharmacological activation that the deacetylase Sirtuin 1 (SIRT1) has an anti-inflammatory role in a less severe, TNF $\alpha^{\text {lo }}$ model of uveitis. We now show that SIRT1 activation fails to clinically suppress severe TNF $\alpha^{\text {hi }}$ disease, whereas glucocorticoid treatment is successful. TNF $\alpha$ has been reported to mediate cleavage and inactivation of SIRT1 during inflammation, and at peak disease we observed both full-length and cleaved SIRT1 in draining lymph node cells. In vivo systemic TNF $\alpha$ blockade suppressed severe ocular disease and restricted SIRT1 cleavage in the periphery, maintaining full-length active SIRT1 protein. When combining a suboptimal TNF $\alpha$ blockade with SIRT1 activation, a synergistic suppression of severe disease compared with TNF $\alpha$ blockade alone occurred. Our data suggest a new role for TNF $\alpha$ in exacerbating the severity of autoimmune disease by regulating SIRT1 cleavage in draining lymph node effector cells. SIRT1 activation may be effective as an adjunctive treatment for inflammatory conditions not fully controlled by TNF $\alpha$ inhibitors. (Am J Pathol 2015, 185: 1324-1333; http://dx.doi.org/10.1016/j.ajpath.2015.01.017)
\end{abstract}

Tumor necrosis factor (TNF) $\alpha$ is a proinflammatory cytokine required for mounting the host response to infection, but whose excessive production can result in many chronic autoimmune pathological features, such as rheumatoid arthritis, type 2 diabetes, and psoriasis. ${ }^{1}$ Although $\mathrm{TNF} \alpha$ can be produced by several cell types, including macrophages, $\mathrm{T}$ cells, natural killer cells, and neutrophils, ${ }^{2}$ the two distinct receptors for TNF $\alpha$ are ubiquitously expressed and downstream signaling of TNF $\alpha$ results in broad effects, such as activation, proliferation, or apoptosis, depending on the specific environment and cell type. ${ }^{3}$ Therapeutic agents that block TNF $\alpha$ activity are widely used in clinical practice for the treatment of chronic inflammatory conditions, including uveitis. Although effective, the immunomodulatory consequences of TNF $\alpha$ blockade are still poorly understood, particularly with regard to predicting and refining patient outcomes. Recent published data suggest that $\mathrm{TNF} \alpha$ can paradoxically promote immunosuppression during chronic inflammation. ${ }^{4}$

The $\mathrm{NAD}^{+}$-dependent histone deacetylase Sirtuin 1 (SIRT1) has been shown to be immunosuppressive, ${ }^{5-8}$ and we have recently demonstrated that its activation in vivo using the small-molecule SIRT1 activator SRT2379 ${ }^{9}$ protects against

Supported by collaborative grant funds from Ophthiris Discovery Performance Unit, GlaxoSmithKline Ophthalmology (Stevenage, UK), and Ophthiris Discovery Performance Unit, GlaxoSmithKline (P.J.G.), and in part via the National Institute for Health Research Biomedical Research Centre at Moorfields Eye Hospital National Health Service Foundation Trust and UCL Institute of Ophthalmology (A.D.D. and V.L.C.).

The views expressed are those of the authors and not necessarily those of the National Health Service, the National Institute for Health Research, or the UK Government Department of Health.

A.D.D. and V.L.C. contributed equally to this work as senior authors.

Disclosures: P.A. is employed by GlaxoSmithKline. 
autoimmune ocular inflammation in mice. ${ }^{10}$ This protection occurs, in part, by suppression of proinflammatory cytokine secretion, such as interferon (IFN)- $\gamma$, IL-17A, and IL-6, and suppression of IL-2-driven T-cell proliferation via the perturbation of STAT5 signaling. ${ }^{10}$ In addition, SIRT1 has also been shown to mediate immune suppression via targeting of histones and numerous proteins, including p53, AP-1, RelA/p65, and STAT3. ${ }^{11-13}$ Recently, TNF $\alpha$ signaling in osteoarthritic chondrocytes has been shown to result in cleavage of the 110$\mathrm{kDa}$ full-length SIRT1 to a 75-kDa form that no longer retains deacetylase activity but can block apoptosis, resulting in the breakdown of cartilage-specific extracellular matrix, as observed in rheumatoid arthritis. ${ }^{14}$ These findings raise important questions about the impact of TNF $\alpha$ on SIRT1 in lymphocytes during autoimmune disease.

We show herein that in a severe model of autoimmune ocular inflammation with extensive tissue destruction, the dominant $\mathrm{CD}^{+}{ }^{+} \mathrm{T}$-cell population infiltrating the eye at disease peak expresses $\mathrm{TNF} \alpha . \mathrm{CD}^{+}{ }^{+} \mathrm{TNF} \alpha^{+}$cells also dominate in peripheral lymphoid tissues at disease peak, where cleavage and inactivation of SIRT1 are observed. Systemic administration of the immunosuppressive SIRT1 activator SRT2379 fails to prevent disease development, except in combination with clinically suboptimal TNF $\alpha$ blockade, suggesting TNF $\alpha$ may have a role in exacerbating and maintaining chronic inflammation via the cleavage of SIRT1 in peripheral lymphocytes. The data shown are important for the application of SIRT1 activators as a therapy for the treatment of systemic autoimmune disease. The potential synergy of combining SIRT1 activators and TNF $\alpha$ antagonists could prove useful to suppress inflammatory conditions not fully controlled by TNF $\alpha$ inhibitors as well as facilitating reduced dosing of TNF $\alpha$ inhibitors and consequently, a decrease of commonly seen adverse effects of TNF $\alpha$ blockade, such as Mycobacterium tuberculosis reactivation.

\section{Materials and Methods}

\section{Mice}

B10.RIII mice were derived originally from The Jackson Laboratory (Bar Harbor, ME) and were obtained from the breeding colony at GlaxoSmithKline (Stevenage, UK). On arrival at the UCL Institute of Ophthalmology (London, UK), all mice were housed in individually ventilated cabinets in specific pathogen-free conditions with continuously available water and food for the duration of all experimental autoimmune uveoretinitis (EAU) studies, according to UK Home Office Regulations. All animal studies were ethically reviewed and performed in accordance with Animals (Scientific Procedures) Act 1986 and the GlaxoSmithKline Policy on the Care, Welfare, and Treatment of Animals. Female mice immunized for EAU disease induction were aged between 5 and 8 weeks. Treatment of animals also conformed to The Association for Research in Vision and Ophthalmology statement for the use of animals in ophthalmic and vision research.

\section{Reagents}

Human interphotoreceptor retinoid-binding protein (IRBP) ${ }_{161-180}$ (SGIPYIISYLHPGNTILHVD) was obtained from Cambridge Peptides (Cambridge, UK) and stored lyophilized at $4^{\circ} \mathrm{C}$ until use. Complete media consisted of Iscove's Modified Dulbecco's Medium (Sigma, Gillingham, UK) supplemented with $10 \%$ fetal calf serum, $0.05 \mathrm{mmol} / \mathrm{L}$ 2-mercaptoethanol (Sigma), $0.1 \mathrm{mmol} / \mathrm{L}$ nonessential amino acids, $1 \%$ minimal essential medium essential vitamin mixture, $100 \mathrm{U} / \mathrm{mL}$ penicillin-streptomycin, and $2 \mathrm{mmol} / \mathrm{L}$ L-glutamine (Life Technologies, Loughborough, UK). Water-soluble dexamethasone (Dex; D2915; Sigma) was dissolved in phosphatebuffered saline. SRT2379 is a small-molecule activator of SIRT1 developed by GlaxoSmithKline (formerly Sirtris Pharmaceuticals Inc, Cambridge, MA), which has been characterized for use in vivo dissolved in $2 \%$ hydroxypropylmethylcellulose $/ 0.2 \%$ dioctyl sodium sulfosuccinate, referred to as vehicle. The soluble TNF $\alpha$ receptor - Ig fusion protein (sTNFR-Ig) was a gift from Dr. Herman Waldmann (University of Oxford, Oxfordshire, UK).

\section{EAU Induction}

B10.RIII mice were immunized s.c. in the flank with $300 \mu \mathrm{g}$ IRBP $_{161-180}$ in phosphate-buffered saline emulsified with complete Freund's adjuvant (Sigma) supplemented with 1.5 $\mathrm{mg} / \mathrm{mL}$ M. tuberculosis complete H37 Ra (Difco Microbiology, Voigt Global Distribution, Lawrence, KS) (1:1 $\mathrm{v} / \mathrm{v})$. The mice also concurrently received $0.4 \mu \mathrm{g}$ Bordetella pertussis toxin (Sigma) i.p.

\section{Fundus Imaging}

The topical endoscopic fundus imaging (TEFI) system $^{15}$ was used for routine in vivo imaging of mouse retinal fundus. TEFI images were clinically scored using a scoring system modified from Copland et $\mathrm{al}^{15}$ (Supplemental Table S1).

\section{Histology}

At day 14 after EAU induction, enucleated eyes were fixed in $4 \%$ glutaraldehyde for 2 hours, followed by overnight fixation in $10 \%$ formalin. Eyes were then processed, orientated, and embedded for paraffin wax sectioning. Eyes were serially cut into sections (7 to $12 \mu \mathrm{m}$ thick), stained with eosin, counterstained with hematoxylin, and scored for disease, as previously published. ${ }^{16}$

\section{Ocular Dissection and Single-Cell Preparation}

Enucleated eyes were dissected in $100 \mu \mathrm{L}$ of cold Dulbecco's modified Eagle's media. After incision at the limbus with a 29-gauge needle, a circumferential cut around the eye following the limbus was made. Iris was dissected away, releasing anterior chamber infiltrating cells into the dissection media. The retina and vitreous were then removed carefully from the eye cup, 
leaving the sclera/retinal pigment epithelium/choroid intact. The dissection media containing anterior fluid, vitreous, and retina were then pipetted up into a $1.5-\mathrm{mL}$ Eppendorf tube and mechanically disrupted by rapping 10 times for a single-cell suspension, followed by centrifugation through a single well of a 96-well, 60- $\mu \mathrm{m}$ cell strainer plate (Millipore, Watford, UK). The resulting cell pellets were resuspended and stained for flow cytometry, as described below.

\section{Flow Cytometry}

Cells were incubated with purified rat anti-mouse CD16/CD32 (Fc $\gamma$ III/II receptor) monoclonal antibody (mAb; Mouse Fc Block; eBioscience, Hatfield, UK), followed by incubation with fluorochrome-conjugated mAbs against cell surface markers on ice. Multiparameter flow cytometry was performed using a combination of mAbs with different fluorochromes. The following mouse-specific mAbs were purchased from eBioscience: $\alpha \mathrm{CD} 4$-phosphatidylethanolamine (PE), $\alpha \mathrm{CD} 4$ $\mathrm{PECy} 7, \alpha \mathrm{IFN} \gamma$-allophycocyanin, $\alpha \mathrm{CD} 11 \mathrm{~b}$-phycoerythrin/Cy 7 , $\alpha \mathrm{CD} 45-$ fluorescein isothiocyanate, $\alpha \mathrm{TNF} \alpha-$ fluorescein isothiocyanate, $\alpha \mathrm{TNF} \alpha$-efluor 450 , and the fixable viability dye efluor 780. $\alpha$ Ly6G-allophycocyanin (clone 1A8) was purchased from Biolegend (London, UK), and the following were purchased from BD Biosciences (Oxford, UK): $\alpha \mathrm{IL}-17-\mathrm{PE}$ and Foxp3-Alexa 488. Cells were washed twice in staining buffer (phosphate-buffered saline with $0.1 \%$ bovine serum albumin and $0.05 \%$ azide) after incubation with fluorochromeconjugated mAbs.

Intracellular IFN $\gamma$ and IL-17 were detected after 4 hours of activation with $50 \mathrm{ng} / \mathrm{mL} 4 \beta$-phorbol 12-myristate 13-acetate, $500 \mathrm{ng} / \mathrm{mL}$ ionomycin, and $1 \mathrm{mg} / \mathrm{mL}$ brefeldin (all from Sigma) in complete Iscove's Modified Dulbecco's Medium. Mouse cells were incubated with Mouse Fc Block and incubated with PE-Cy7-conjugated anti-CD4 mAb, before permeabilization using the BD Perm/Fix kit (BD Biosciences), according to the manufacturer's instructions, and intracellular staining with the appropriate mAbs. Cells were washed before analysis.

Transcription factor analysis was performed using the Foxp3 Cell Staining Kit (BD Biosciences), according to the manufacturer's instructions. Relevant isotype control mAbs were purchased from BD Biosciences and eBioscience and combined as fluorescence minus one controls. Cells were acquired on a BD FACSCalibur using CellQuest (BD Cytometry Systems, Oxford, UK) and a BD LSRFortessa-x20 using FACSDiva (BD Cytometry Systems). Single-stained beads (OnceComp eBeads; eBioscience, London, UK) of all fluorochromes were used to generate appropriate compensation matrices, and fluorescence minus one controls were used for positive gating. Flow cytometric analyses were performed using FlowJo Software (TreeStar, Ashland, OR).

\section{Western Blot Analysis}

Western blot detection of both full-length and cleaved SIRT1 was performed on $70 \mu \mathrm{g}$ total protein cell extract from mouse dLN cells pooled from three animals. Cells were lysed in radioimmunoprecipitation assay lysis buffer containing 1:100 freshly added protease inhibitor cocktail (Sigma) with shaking for 20 minutes at $4^{\circ} \mathrm{C}$. Proteins were separated using 9\% SDS-PAGE and blotted to Immobilon-P transfer membrane (Millipore), followed by detection with aSIRT1 N-terminal polyclonal antibody (07-131; Millipore). This was followed by incubation with secondary Goat $\alpha$-Rabbit-HRP (7074; Cell Signaling Danvers, MA) and subsequent development with an ECL Plus detection kit (Amersham, GE Healthcare, Little Chalfont, UK). ImageJ software (NIH, Bethesda, MD) was used for quantification.

\section{Cytokine Detection}

Cell supernatant cytokines were determined by use of TNF $\alpha$ Quantikine enzyme-linked immunosorbent assay (R\&D Systems Europe Ltd, Abingdon, UK) and multiplex bead array using a Luminex 100 System (Austin, TX) and the type 17 helper T-cell (Th17) six-plex kit (Bio-Rad, Hemel Hempstead, UK), following the manufacturer's instructions as described. ${ }^{10}$ The data were analyzed using the xPONENT version 3.1 analysis software (Luminex).

\section{Statistical Analysis}

Data were analyzed using the following statistical tests, as described in the figure legends for each individual experiment: unpaired two-tailed $t$-test, one-way analysis of variance multiple comparisons, two-way analysis of variance, $U$-test, and the Kruskal-Wallis test, all using Prism software version 5.0 (Graphpad Software, La Jolla, CA).

\section{Results}

Severe Ocular Inflammation in B10.RIII Mice Peaks at Day 14 and Is Dominated by Neutrophils and $\mathrm{CD}^{+}{ }^{+} \mathrm{TNF} \alpha^{+}$Cells Infiltrating the Eye

In the B10.RIII colony, induction with $300 \mu \mathrm{g} \mathrm{IRBP}_{161-180}$ and $0.4 \mu \mathrm{g}$ of pertussis toxin results in ocular disease, which, by fundal examination (TEFI), manifests at day 8 with mild optic disc swelling, peaks at day 14 with anterior synechiae and foci of preretinal hemorrhage, and after acute disease inflammation, persists until day 95 , where the presence of scar tissue can be observed (Figure 1A and Supplemental Figure S1A). At day 14, EAU examination of the cornea and anterior chamber revealed the presence of erythrocytes (Supplemental Figure S1, B and C), and examination of dissected whole retina compared to complete Freund's adjuvant controls (Supplemental Figure S1, $\mathrm{D}$ and $\mathrm{E}$ ) revealed patches of hemorrhage and patches of retinal pigment epithelial cells adherent to the retina (Supplemental Figure S1E).

Histological processing of eyes at day 14 EAU compared to eyes from complete Freund's adjuvant 
A

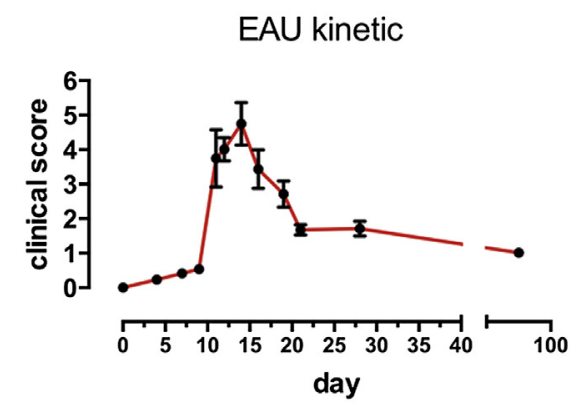

I

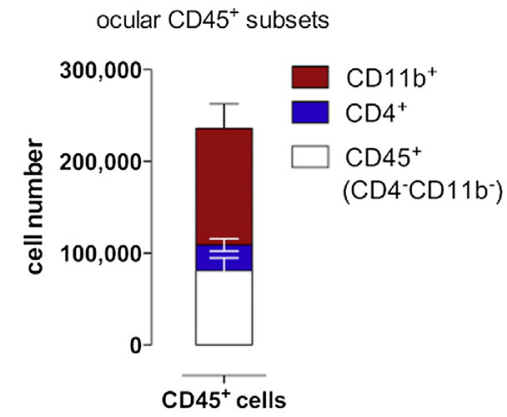

$\mathbf{K}$
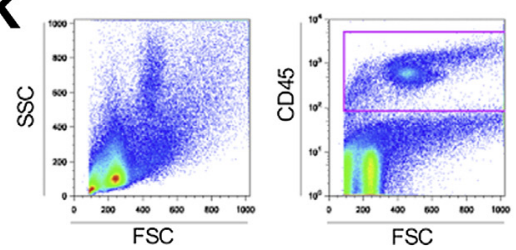

$\mathrm{CD} 4^{+} \mathrm{T}$ helper subsets

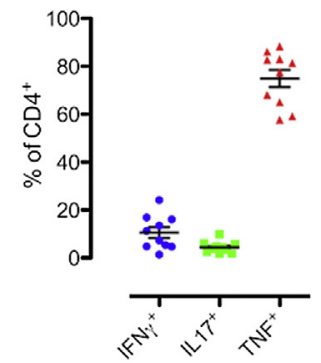

B

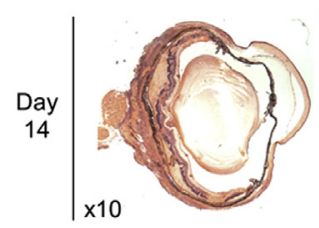

$\mathbf{F}$

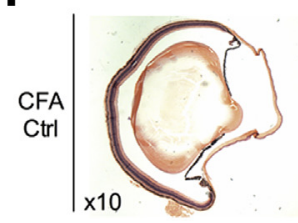

G

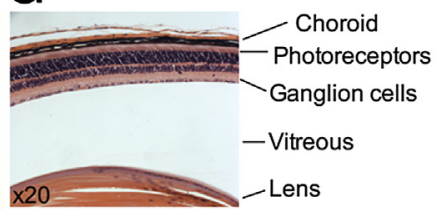

H

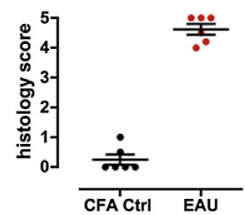

$\mathbf{J}$
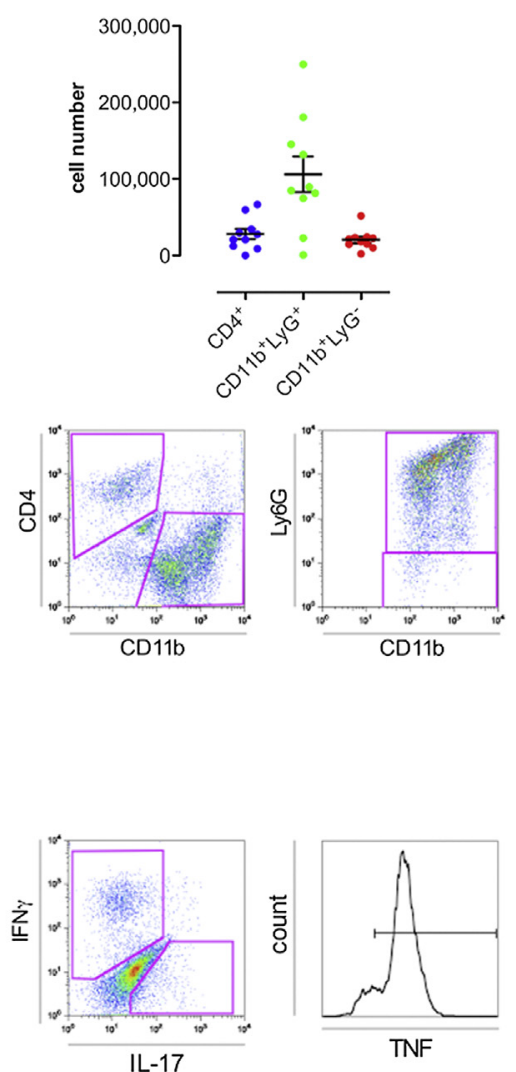

Figure 1 Severe ocular inflammation in B10.RIII mice peaks at day 14 with complete photoreceptor outer segment loss and is dominated by neutrophils and $\mathrm{CD}^{+}$tumor necrosis factor (TNF) $\alpha^{+}$cells infiltrating the eye. A: Mean clinical scores from topical endoscopic fundus imaging: from day 4 to day 95 of experimental autoimmune uveoretinitis (EAU). B-H: Representative histology at day 14 of EAU and complete Freund's adjuvant (CFA) immunized eyes. EAU eye (B), with magnification $(\mathbf{C})$ of the anterior chamber. Arrows show inflamed ciliary body and anterior synechiae. D: Magnification of EAU retina. Arrows indicate vessel hemorrhage and exudate. E: Magnification of retina/ vitreous with erythrocyte leakage. F: CFA control (Ctrl) eye. G: Magnification of CFA retina. H: Histology scores for EAU disease at day 14, average of two blinded scorers (P.J.G. and S.Y.). I: Combined total CD45 ${ }^{+}$ ocular infiltrate broken down into myeloid and $\mathrm{CD}^{+}$ cells by subset. J: Spread of absolute counts of ocular infiltrating $\mathrm{CD} 45^{+}$leukocytes at peak disease by subset. K: Representative flow cytometry plots showing the gating strategy for leukocyte staining. L: $\mathrm{CD}^{+}{ }^{\mathrm{T}}$-cell subsets infiltrating the whole eye at peak disease after ex vivo restimulation with $4 \beta$-phorbol 12 -myristate 13 acetate/ionomycin with brefeldin, followed by intracellular cytokine staining, with representative flow cytometry plots showing gating. Data are given as means \pm SEM $(\mathbf{I}-\mathbf{K}) . n=6$ eyes $(\mathbf{H}) ; n=10$ eyes $(\mathbf{I}, \mathbf{J}$, and $\mathbf{L})$. Original magnifications: $\times 20(\mathbf{C}, \mathbf{D}$, and $\mathbf{G})$; $\times 40$ (E). C, choroid; Cm, cornea; FSC, forward scatter; $\mathrm{G}$, ganglion layer; IFN, interferon; $\mathrm{L}$, lens; $\mathrm{P}$, photoreceptor layer; SSC, standard saline citrate; V, vitreous. immunized control mice revealed the near-total loss of photoreceptors with massive retinal exudate (Figure 1, B and D) and confirmed the presence of anterior synechiae (Figure 1C) and retinal hemorrhage with erythrocytes observed in the vitreous (Figure 1, D and E) as compared to complete Freunds' adjuvant control eyes (Figure 1, F and G). Histological scoring of sections showed that day 14 EAU eyes were at the top of our scoring spectrum, reflecting the targeted immune response resulting in near-total loss of the photoreceptors, which express the target antigen IRBP (Figure 1H).

Analysis of the ocular infiltrate at the peak of disease by flow cytometry revealed a substantial infiltration of leukocytes composed of myeloid cells and $\mathrm{CD} 4^{+} \mathrm{T}$ cells with a dominant $\mathrm{CD} 11 \mathrm{~b}^{+} \mathrm{Ly}_{6 \mathrm{G}}{ }^{+}$neutrophil population (Figure 1 , I and $\mathrm{J}$ ).

Analysis of whole ocular infiltrating $\mathrm{CD} 4^{+} \mathrm{T}$-cell subsets by intracellular cytokine staining demonstrated the previously reported and expected presence of $\mathrm{IFN}^{+}$(mean, $10.6 \% ; \mathrm{SD}, \pm 7.1 \%$ ) and $\mathrm{IL}^{-17 \mathrm{~A}^{+}}$(mean, 4.4\%; $\mathrm{SD}, \pm 2.5 \%$ ) cells, but the dominant population of $\mathrm{T}$ cells expressed TNF $\alpha$ (mean, $74.9 \%$; SD, $\pm 11.4 \%$ ) (Figure 1L) and, hence, we refer to these mice, in terms of the T-cell response during uveitis, as $\mathrm{TNF} \alpha^{\mathrm{hi}}$.

Analysis of ocular infiltrating $\mathrm{CD} 4^{+} \mathrm{T}$ cells at peak disease in mice, previously published by us, where IFN $\gamma^{+}$cells 
A

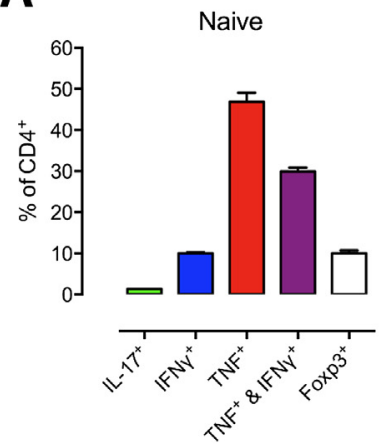

peak EAU

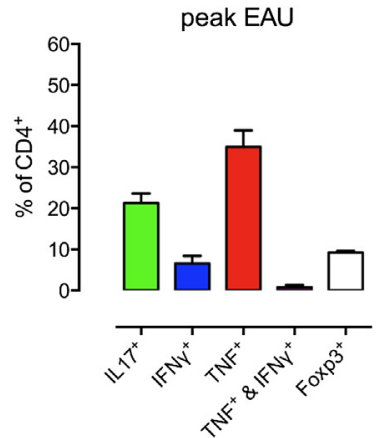

B

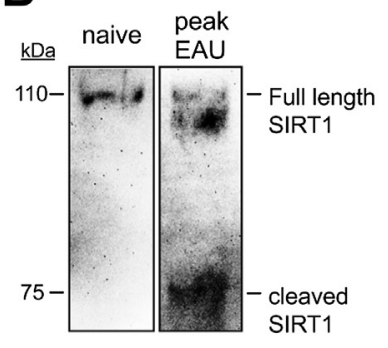

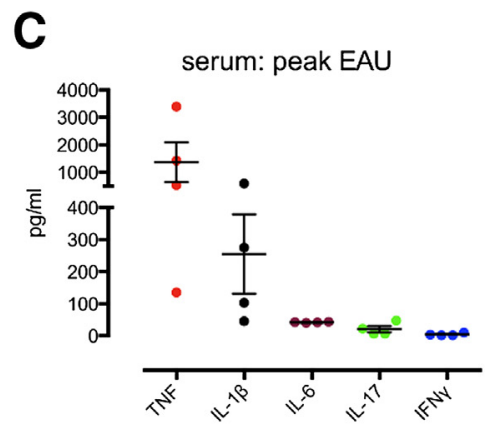

Figure 2 Severe $\mathrm{CD}^{+}$tumor necrosis factor (TNF) $\alpha^{+}$-driven experimental autoimmune uveoretinitis (EAU) disease is associated with SIRT1 cleavage in draining lymph nodes. A: Flow cytometry analysis of ex vivo $\mathrm{CD}^{+} \mathrm{T}$-cell subsets by intracellular cytokine staining from naïve animals or animals with peak EAU disease. B: Western blot of SIRT1 from draining lymph node cells pooled from three animals comparing complete Freund's adjuvant control animals with peak EAU disease animals. C: Plasma cytokine levels. Data are given as means \pm SEM (A and C). $n=4$ animals (A and C). IFN, interferon.

and IL-17A $\mathrm{A}^{+}$cells make up a mean of $19.3 \%(\mathrm{SD}, \pm 16.6 \%)$ and $15.5 \%$ (SD, $\pm 9.8 \%)$, respectively, ${ }^{10}$ revealed that $\mathrm{TNF} \alpha^{+}$cells constitute only $31.1 \%(\mathrm{SD}, \pm 2.1 \%)$ of the $\mathrm{CD} 4^{+}$population. Hence, we term $\mathrm{TNF} \alpha^{\text {lo }}$ mice, with respect to the T-cell phenotype during disease (Supplemental Figure S2). We have access then to two B10.RIII colonies that manifest as $\mathrm{TNF}^{\text {hi }}$ and $\mathrm{TNF}^{\mathrm{lo}}$ EAU disease with differential severity following an identical disease induction protocol (Supplemental Figure S2). Analysis of SIRT1 protein by Western blot analysis at peak EAU disease revealed minimal cleavage of SIRT1 in TNF ${ }^{\text {lo }}$ mice (Supplemental Figure S2); hence, we have used these two different manifestations of autoimmune pathology to interrogate the effect of TNF on SIRT1 function.

\section{Severe $\mathrm{CD} 4^{+} \mathrm{TNF} \alpha^{+}$-Driven EAU Disease Is Associated with SIRT1 Cleavage in Draining Lymph Nodes}

Analysis of peripheral lymphoid tissue in B10.RIII mice revealed a dominant $\mathrm{CD} 4^{+} \mathrm{TNF} \alpha^{+}$population in cells restimulated from both naïve and peak EAU disease mice, with an IL-17A population also participating in disease (Figure 2A). TNF $\alpha$ has recently been shown to regulate cleavage of SIRT1 within chondrocytes during inflammation ${ }^{14}$; hence, we investigated SIRT1 in the periphery of the EAU mice. Analysis of SIRT1 in dLN cells revealed only full-length active SIRT1 in naive animals and the presence of both fulllength and the inactive cleaved form of SIRT1 in cells from mice at peak disease (Figure 2B). Analysis of plasma cytokines in peak EAU mice revealed high levels of circulating systemic $\mathrm{TNF} \alpha$ and the presence of IL- $1 \beta$ and low levels of IL- 6 (Figure 2C).

\section{Prophylactic Systemic SIRT1 Activation in Vivo Fails to Prevent Disease Development during TNF $\alpha^{\text {hi }}$ Severe EAU Disease}

We have previously shown suppression of milder expressed ocular inflammatory disease in B10.RIII mice using the
SIRT1 activator SRT $2379^{10}$; hence, we investigated the ability of SRT2379 to suppress severe TNF $\alpha^{\text {hi }}$ disease. We predicted that, in the presence of high TNF $\alpha$ levels, the action of the SIRT1 activator would be negated. B10.RIII mice administered with 10,30 , and $100 \mathrm{mg} / \mathrm{kg}$ SRT2379 by once-daily oral gavage from the time of immunization until peak EAU had histological disease scores indistinguishable from vehicle-treated mice (Figure 3, A and B), whereas systemic Dex by daily i.p. injection from the day of EAU induction, which has been shown to suppress disease in mice, ${ }^{17}$ significantly reduced disease $(P<0.0001, n=6)$. Corticosteroid treatment prevented extensive structural changes to the retina, limiting changes to cellular infiltration in the vitreous, perivascular cuffing, and mild retinal folding (Figure 3B).

In SIRT1 activator-treated mice, we observed significantly reduced $\mathrm{CD}_{4} 5^{+}$ocular infiltrate with $100 \mathrm{mg} / \mathrm{kg}$ SRT2379 of 38\% compared to vehicle $(P=0.0499)$ (Figure 3, C and D); however, ocular infiltrating CD11 b ${ }^{+} \mathrm{Ly}_{6 \mathrm{G}}{ }^{+}$ and $\mathrm{CD} 11 \mathrm{~b}^{+} \mathrm{Ly}_{6 \mathrm{G}}^{-}$were unchanged (Figure 3E). The overall number of $\mathrm{CD} 4^{+}$cells was reduced by $51 \%$ when compared to vehicle $(P=0.0199)$ (Figure 3F).

Analysis of $\mathrm{CD}^{+}{ }^{+} \mathrm{T}$-cell subsets revealed no specific effects of SRT2379 on proportions of intracellular cytokine expression in ocular infiltrating $\mathrm{CD} 4^{+} \mathrm{T}$ cells (Supplemental Figure S3). We published previously that SIRT1 activation with SRT2379 abolished IL-17A and IL-6 production by dLN cells from TNF ${ }^{\text {lo }}$ EAU mice. ${ }^{10}$ Analysis of cytokine production by ex vivo cultured $\mathrm{dLN}$ cells from $\mathrm{TNF} \alpha^{\mathrm{hi}}$ SRT2379-treated EAU mice, unstimulated or restimulated with $20 \mu \mathrm{g} / \mathrm{mL}$ IRBP $_{161-180}$ peptide for 48 hours, showed significant, but limited, suppression of IL-17A levels at the $100 \mathrm{mg} / \mathrm{kg}$ dose, whereas significant suppression of IL-6 was observed at both doses irrespective of stimulation (Figure 3G). SIRT1 activator efficacy of the same batch of compound was tested contemporaneously in the $\mathrm{TNF}^{\mathrm{lo}}$ mice throughout the period of the study with the $\mathrm{TNF}^{\mathrm{hi}}$ mice, to ensure that the observed decreased compound activity did not account for the lack of efficacy in the TNF ${ }^{\text {hi }}$ mice. 
A
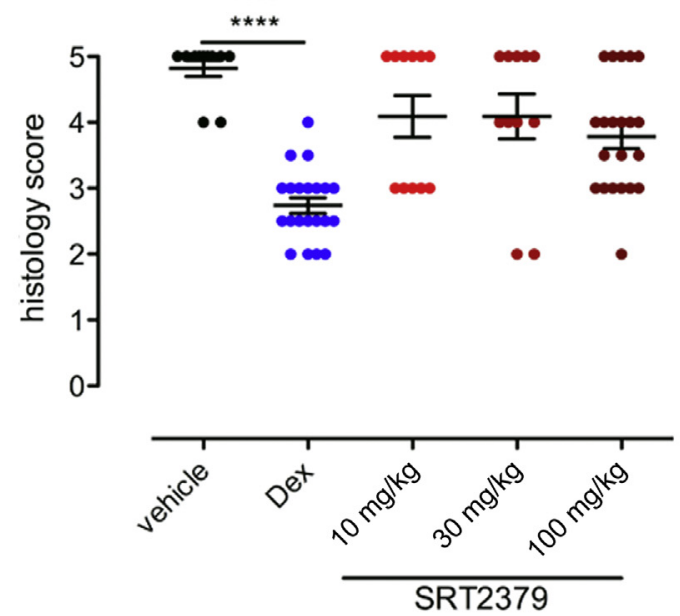

C

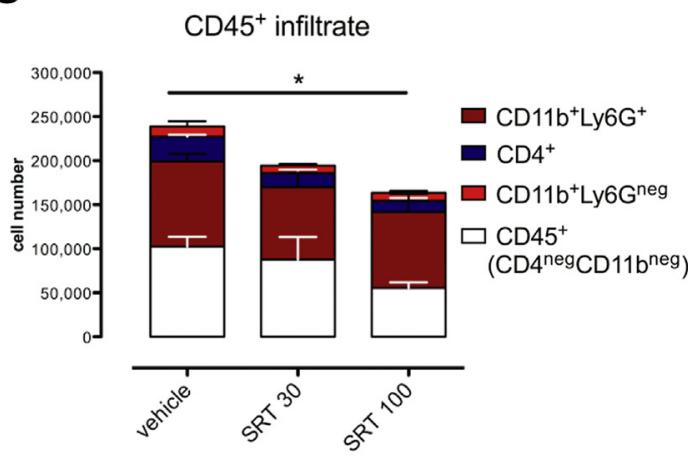

G

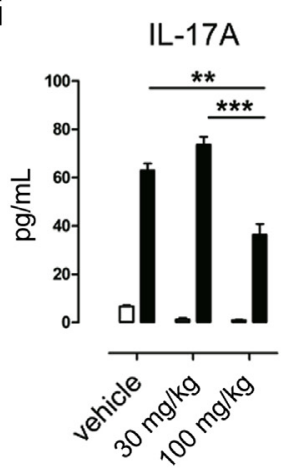

B

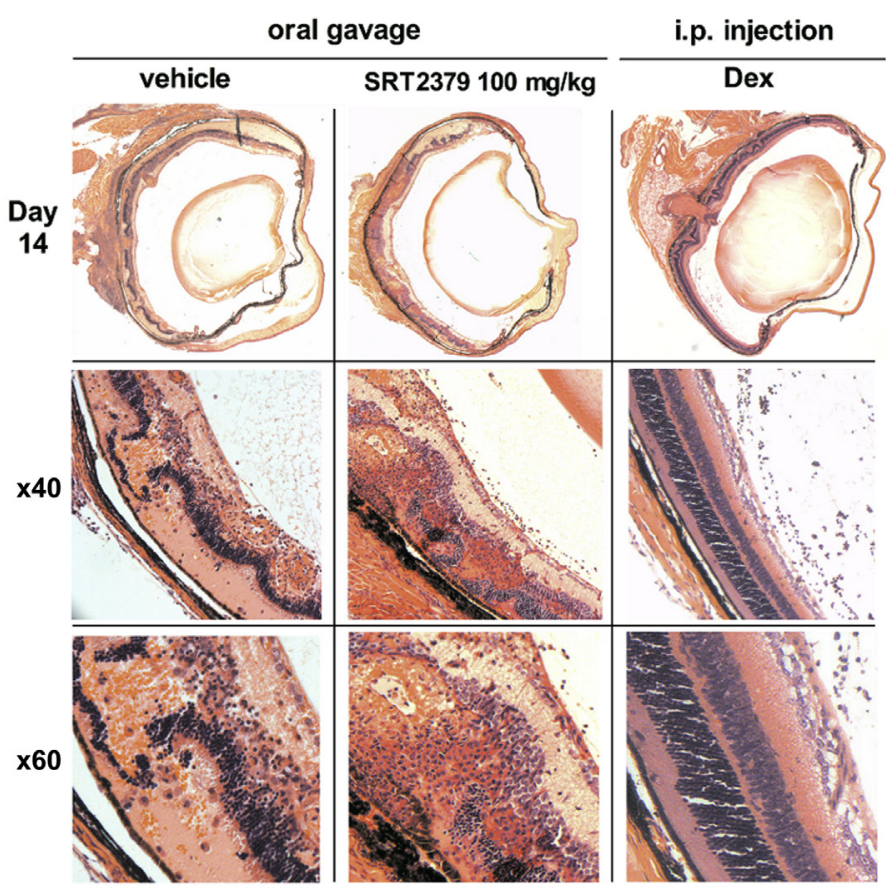

D

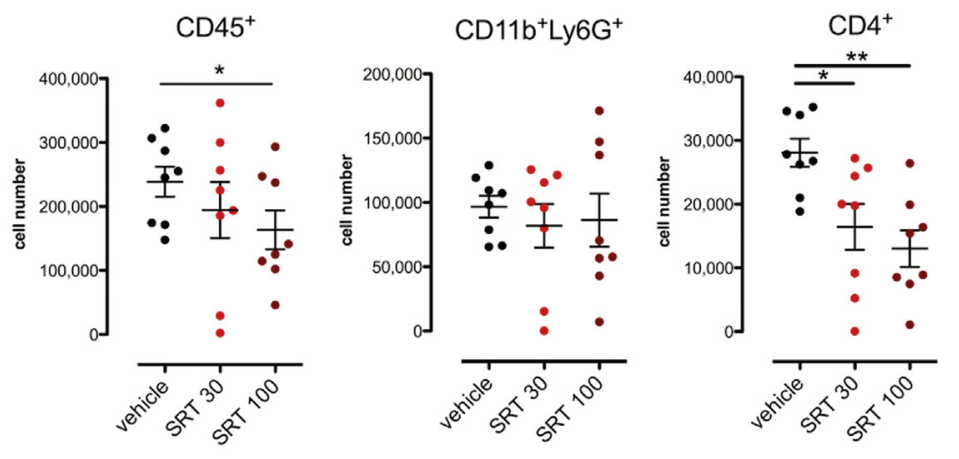

Systemic Blockade of TNF $\alpha$ during EAU Suppresses Disease and Restricts SIRT1 Cleavage in Peripheral Lymphoid Tissue

Given our finding that during TNF $\alpha^{\text {hi }}$ EAU, SIRT1 is cleaved in the periphery and SIRT1 activator treatment is limited, we sought to test the notion that SIRT1 activatormediated immune suppression could be restored on neutralization of systemic TNF $\alpha$. To accomplish this, we required the means of attenuating systemic TNF $\alpha$ levels such that full-length SIRT1 would be protected from cleavage, without the complete abrogation of disease. Blockade of $\mathrm{TNF} \alpha$ during EAU using a recombinant sTNFR-Ig has been shown to be successful in preventing and reducing the severity of pathology. ${ }^{18}$ It has been proposed that the main action of sTNFR-Ig is via modulation 

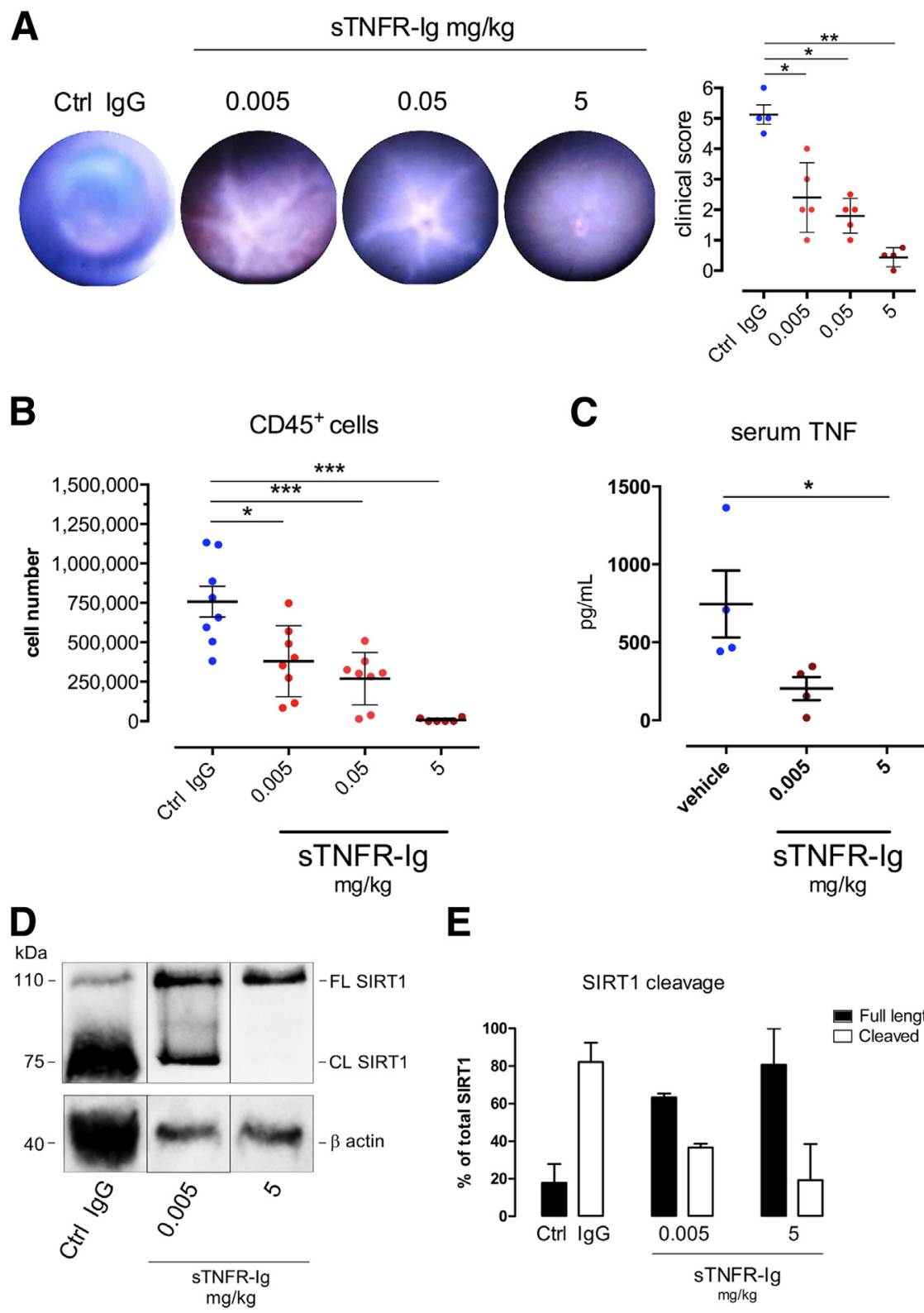

Figure 4 Systemic blockade of tumor necrosis factor (TNF) $\alpha$ during experimental autoimmune uveoretinitis (EAU) suppresses disease and restricts SIRT1 cleavage in peripheral lymphoid tissue. A: Representative topical endoscopic fundus images of animals at day 12 EAU treated at day 9 with a single i.p. injection of control (Ctrl) IgG or varying doses of recombinant soluble TNF $\alpha$ receptor-Ig fusion protein (sTNFR-Ig), as indicated, with mean clinical scores. B: Quantification of the $\mathrm{CD}_{4} 5^{+}$ocular infiltrate at day 14 by flow cytometry. C: Serum levels of TNF $\alpha$ in peak EAU mice treated as indicated. D: Western blot of SIRT1 on $70 \mu \mathrm{g}$ total protein from draining lymph node cells pooled from five peak EAU animals comparing control IgG treatment with indicated doses of sTNFR-Ig treatment. E: Combined quantification of two Western blots from two independent experiments using ImageJ analysis. Data are given as means \pm SEM (A-C and $\mathbf{E}) . n=8$ eyes $(\mathbf{B}) ; n=4$ animals (C). ${ }^{*} P \leq 0.05,{ }^{*} P \leq 0.01$, and $* * * P \leq 0.001$. CL, cleaved; FL, full length.

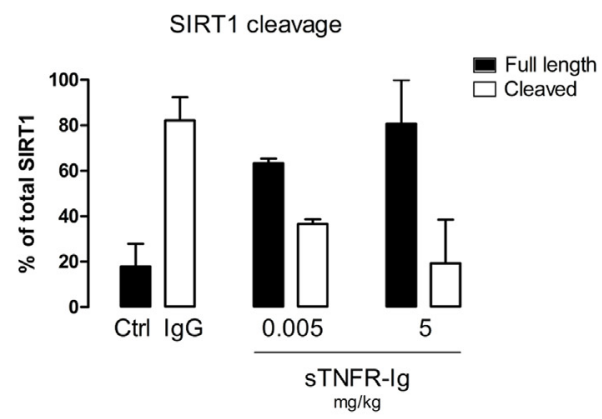

of T-cell phenotype, function, ${ }^{19}$ and neutralization of T-cellproduced soluble $\mathrm{TNF} \alpha$ and transmembrane $\mathrm{TNF} \alpha$, acting to minimize the activation of infiltrating inflammatory monocytes and macrophages. ${ }^{20}$ Treatment of the severe TNF $\alpha^{\text {hi }}$ EAU mice with sTNFR-Ig resulted in a dose-titrated reduction in disease, as observed by TEFI clinical examination and scoring (Figure 4A) and quantification of $\mathrm{CD}^{4} 5^{+}$ocular infiltrate (Figure 4B). Analysis of systemic TNF $\alpha$ levels revealed that the $0.005 \mathrm{mg} / \mathrm{kg}$ dose resulted in suppression, but not complete abrogation, of $\mathrm{TNF} \alpha$ compared to control IgG treatment, whereas at the $5 \mathrm{mg} / \mathrm{kg}$ dose, TNF $\alpha$ was not detected (Figure 4C). We next assessed the effect of TNF $\alpha$ blockade on SIRT1 cleavage. Analysis of SIRT1 by Western blot analysis in dLN cells from EAU mice treated with sTNFR-Ig revealed a predominantly intact, full-length SIRT1 was present, with minimal SIRT1 cleavage product observed in the $5 \mathrm{mg} / \mathrm{kg}$ sTNFR-Ig-treated group as compared to cells from control IgG-treated mice with partially cleaved SIRT1 present at the lower $0.005 \mathrm{mg} / \mathrm{kg}$ sTNFR-Ig-treated group (Figure 4, D and E).

\section{Combining TNF $\alpha$ Blockade with SIRT1 Activation} Results in Synergistic Suppression Compared to TNF $\alpha$ Blockade Alone

Because neutralization of $\mathrm{TNF} \alpha$ resulted in prevention of SIRT1 cleavage in dLN cells during EAU, we sought to recover SIRT1 activator-mediated immune suppression via combination with TNF $\alpha$ blockade. For this, we chose the $0.005 \mathrm{mg} / \mathrm{kg}$ dose of sTNFR-Ig, having shown significant suppression of serum TNF $\alpha$ levels with this dose and protection of full-length SIRT1 without abolishing disease. 
Indeed, the combination of TNF $\alpha$ blockade with $100 \mathrm{mg} / \mathrm{kg}$ systemic SRT2379 treatment during EAU resulted in synergistic suppression of $\mathrm{CD}_{4} 5^{+}$ocular infiltrate over that observed with sTNFR-Ig treatment alone (Figure 5A). We also observed significant reduction of $\mathrm{CD} 4^{+} \mathrm{TNF} \alpha^{+} \mathrm{T}$ cells, as determined by intracellular cytokine staining, compared with the sTNFR-Ig alone treated group (Figure 5B). Of the infiltrating $\mathrm{CD}_{4} 5^{+}$cells observed in the combination treated group, cellular proportions were changed, with a marked reduction in neutrophils (Figure 5C). Histological analysis of combination treated eyes revealed that the reduction in cellular burden was sufficiently lower than a threshold required to manifest tissue damage (Figure 5D), with a mean disease score of 1 compared with the sTNFR-Ig-treated group, which maintained disease scores with a mean of 3 (Figure 5E).

\section{Discussion}

TNF $\alpha$ is a pleiotropic cytokine that plays central roles in both driving and regulating multiple autoimmune diseases, ${ }^{1,21}$ including human uveitis. ${ }^{22}$ Indeed, an increased risk of uveitis has been shown to correlate with polymorphisms that result in increased TNF $\alpha$ production. ${ }^{23}$ Although anti-TNF $\alpha$ agents have proved successful in rheumatoid arthritis and uveitis, where high systemic TNF $\alpha$ levels contribute to disease progression, ${ }^{24}$ a paradox regarding the precise role of $\mathrm{TNF} \alpha$ remains in the context of immune-mediated tissue damage, with data both for ${ }^{25-27}$ and against ${ }^{4,28,29}$ the proinflammatory role of TNF $\alpha$. Recent reports have described how inflammatory cues via TNF $\alpha$ result in cleavage of the deacetylase SIRT1 within osteoarthritic chondrocytes, resulting in joint damage, ${ }^{14}$ and we have shown recently that SIRT1 activation is immunosuppressive in $\mathrm{T}$ cells during autoimmune disease. Herein, we used a TNF $\alpha^{\text {hi }}$ severe model of autoimmune ocular inflammation in mice to interrogate the impact of high TNF $\alpha$ levels on SIRT1 function during autoimmunity. We show that TNF $\alpha$ determines disease severity, in part, through initiating cleavage of SIRT1 in lymphocytes, rendering prophylactic SIRT1 activator administration ineffective at suppressing disease.

Our data reveal that severe autoimmune ocular pathology associates with a high TNF $\alpha$ profile, suggesting a role for $\mathrm{CD}^{+}{ }^{+} \mathrm{TNF}^{+}$cells in driving autoimmune disease. The severity, pathological features, and retinal damage observed at peak disease are greater than those reported in other B10.RIII mouse colonies in the literature. ${ }^{30-33}$ B10.RIII mice are naturally high Th1/Th17 responders ${ }^{34}$; however, we show that $\mathrm{TNF} \alpha$-producing $\mathrm{CD} 4^{+}$cells dominate both the ocular infiltrate and peripheral lymphoid tissue at peak disease, with a striking elevation of serum TNF $\alpha$. TNF $\alpha$ expression in ocular infiltrate is a consistent feature of EAU, with TNF $\alpha$ acting to trigger macrophage expression of nitric oxide synthase 2-producing nitric oxide and superoxides, which lead to tissue destruction. ${ }^{35}$ Although TNF $\alpha$ is produced by many cell types, T cell-derived TNF $\alpha$ (relatively
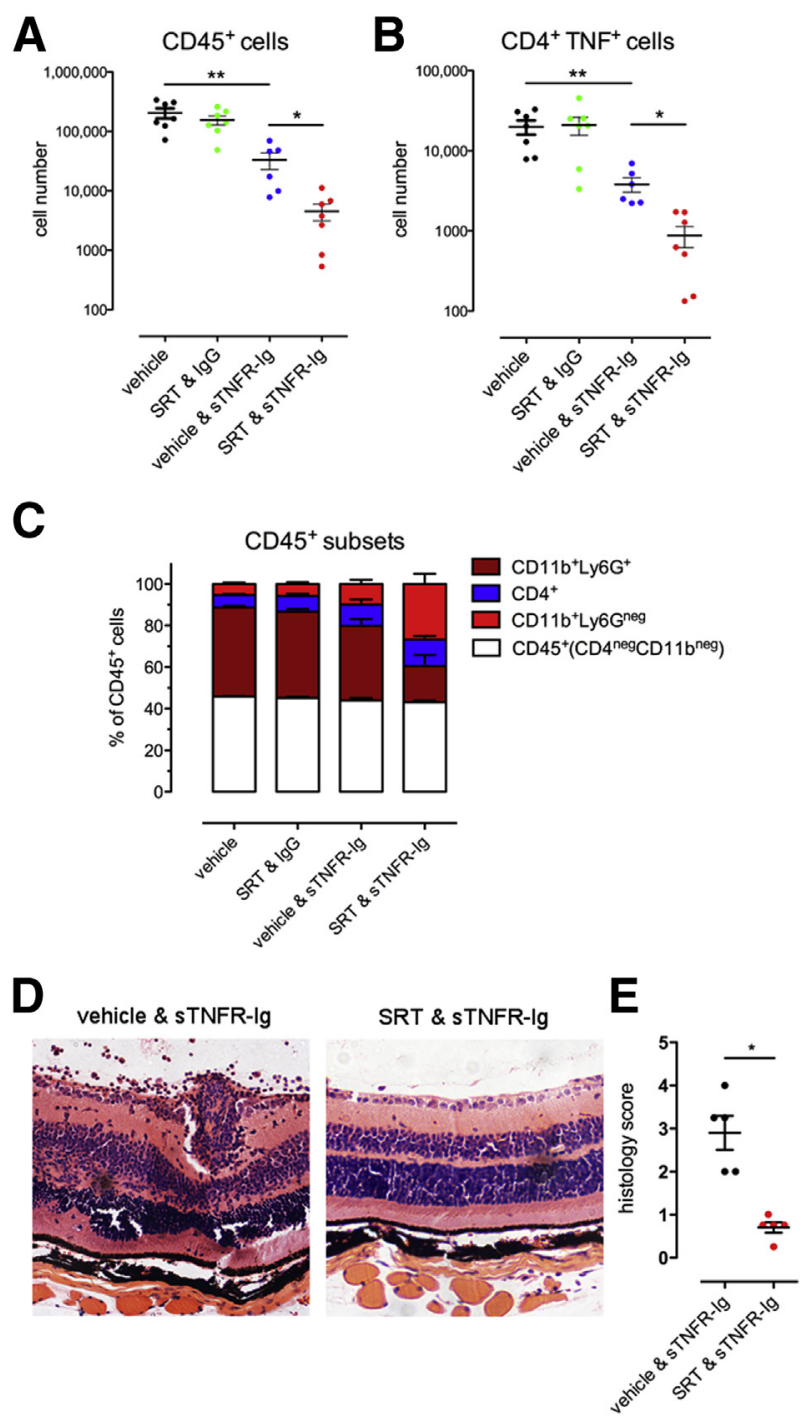

Figure 5 Combining tumor necrosis factor (TNF) $\alpha$ blockade with SIRT1 activation results in synergistic suppression compared with TNF $\alpha$ blockade alone. A: Quantification of $\mathrm{CD}_{4} 5^{+}$ocular infiltrate at peak disease by flow cytometry. B: Quantification of the $\mathrm{CD}^{+}{ }^{+} \mathrm{TNF}^{+}$ocular infiltrating cells at peak disease by flow cytometry. C: Leukocyte subset proportions of total CD $45^{+}$ infiltrate. D: Representative histology of peak disease eyes from soluble TNF $\alpha$ receptor-Ig fusion protein (sTNFR-Ig) day 9 -treated animals combined with either oral gavage treatment with vehicle or SRT2379 from day 0 to peak. E: Mean histology disease scores of two independently blinded scores (P.J.G. and S.Y.). Data are given as means \pm SEM (A-C and E). $n=6$ to 8 eyes per group (A and $\mathbf{B}) ; n=6$ eyes $(\mathbf{E}) .{ }^{*} P \leq 0.05,{ }^{*} P \leq 0.01$.

underexplored in autoimmunity) has been shown to be nonredundant in protecting from high bacterial load, ${ }^{36,37}$ and to contribute to liver damage during hepatitis ${ }^{2}$ and lung inflammation. ${ }^{38}$ It is possible that the $\mathrm{CD} 4^{+} \mathrm{TNF} \alpha^{+}$ cells observed in ocular inflammation have a high level of transmembrane $\mathrm{TNF} \alpha$, which can bind to TNF $\alpha$ receptors on monocytes, resulting in monocyte activation and further TNF $\alpha$ production. ${ }^{39}$

We have shown previously the immunosuppressive effects of SIRT1 during mild non-TNF $\alpha$-dominant EAU in B10.RIII mice. ${ }^{10}$ SIRT1 activator administration to TNF $\alpha^{\text {hi }}$ 
severe EAU mice did not result in prevention of disease. Although infiltrating $\mathrm{CD}^{+}$T-cell numbers were reduced, infiltrating $\mathrm{CD}_{11 \mathrm{~b}^{+}}$cells, which ultimately mediate tissue destruction, were unchanged compared to vehicle controls. Although IL-6 levels produced by ex vivo dLN cultures were suppressed, IL-17A levels in response to antigen stimulation were not abrogated by SIRT1 activator administration in $\mathrm{TNF} \alpha^{\text {hi }}$ severe EAU mice, as previously reported, ${ }^{10}$ suggesting that myeloid cells are more sensitive to SIRT1 activation than $\mathrm{T}$ cells in the context of TNF $\alpha$-mediated partial SIRT1 cleavage. This lack of suppression of IL-17, a known neutrophil chemoattractant, may explain why $\mathrm{CD} 11 \mathrm{~b}^{+} \mathrm{Ly}_{6 \mathrm{G}}{ }^{+}$ infiltrating cell numbers were unchanged after SIRT1 activator treatment.

Glucocorticoids remain first-line therapy for posterior uveitis, ${ }^{40}$ and Dex has been shown to curtail Th1-dominant autoimmune disease ${ }^{41}$ by suppressing TNF $\alpha$-induced granulocyte adhesion ${ }^{42}$ and directly targeting TNF $\alpha$ production in the retina. ${ }^{43}$ Effective prevention of disease by Dex implies that the lack of immunosuppression by SIRT1 activation may result from changes to SIRT1 during disease and exposure to high levels of $\mathrm{TNF} \alpha$ and suggests that Dex effectively targeted the dominant autoreactive $\mathrm{CD} 4{ }^{+} \mathrm{TNF} \alpha^{+}$cells.

The cleavage of full-length SIRT1 to an inactive form has been shown to be mediated by TNF $\alpha$ in chondrocytes, ${ }^{14}$ with an anti-apoptotic role for the cleaved $75-\mathrm{kDa}$ fragment. ${ }^{44}$ Our data support the observation that cleavage of SIRT1 in dLNs occurs during $\mathrm{TNF} \alpha^{\text {hi }}$ disease; however, whether the 75-kDa SIRT1 fragment is protective against apoptosis in lymphocytes remains to be determined. That some full-length SIRT1 protein remains in dLNs may explain the limited suppression of ocular infiltrate in the absence of disease prevention following SIRT1 activator administration. Systemic blockade of TNF $\alpha$ during EAU reveals both the crucial role of $\mathrm{TNF} \alpha$ in driving disease in this mouse model of autoimmunity and the impact of TNF $\alpha$ on SIRT1 cleavage. Indeed, suboptimal attenuation of TNF $\alpha$ levels with respect to suppression of disease and serum TNF $\alpha$ levels still prevented SIRT1 cleavage such that combined treatment with a SIRT1 activator resulted in superior suppression of disease over TNF $\alpha$ blockade alone. The implication is that systemic $\mathrm{TNF} \alpha$ levels may regulate the balance between full-length active and cleaved inactive SIRT1 and, in doing so, determine the threshold above which SIRT1 activation would no longer be effective at suppressing autoimmune disease.

In summary, SIRT1 activator treatment for autoimmunity may be most effective in combination with anti-TNF $\alpha$ therapy or in inflammatory conditions in which TNF $\alpha$ is not a dominant contributor to the disease process and, hence, full-length SIRT1 remains intact. Indeed, it is common clinical practice to combine immunosuppressive drugs in the treatment of human uveitis; however, caution must be exercised regarding any potential adverse effects of SIRT1 activator therapies, which may impede p53 activation. ${ }^{45} \mathrm{We}$ highlight the interplay between $\mathrm{TNF} \alpha$ and the function of SIRT1 within peripheral lymphocytes during developing ocular autoimmune disease and emphasize the importance of characterizing the level of TNF $\alpha$ present during autoimmune disease and inflammation for the successful future use of sirtuin-activator therapies.

\section{Acknowledgments}

We thank Shannon Bunker for help with the dosing of mice, Jennifer Williams for administration of the collaborative grant, and Herman Waldmann (University of Oxford, Oxfordshire, UK) for providing soluble tumor necrosis factor $\alpha$ receptor - Ig fusion protein.

\section{Supplemental Data}

Supplemental material for this article can be found at http://dx.doi.org/10.1016/j.ajpath.2015.01.017.

\section{References}

1. Feldmann M, Maini RN: TNF defined as a therapeutic target for rheumatoid arthritis and other autoimmune diseases. Nat Med 2003, 9: $1245-1250$

2. Grivennikov SI, Tumanov AV, Liepinsh DJ, Kruglov AA, Marakusha BI, Shakhov AN, Murakami T, Drutskaya LN, Förster I, Clausen BE, Tessarollo L, Ryffel B, Kuprash DV, Nedospasov SA: Distinct and nonredundant in vivo functions of TNF produced by $\mathrm{T}$ cells and macrophages/neutrophils: protective and deleterious effects. Immunity 2005, 22:93-104

3. MacEwan DJ: TNF receptor subtype signalling: differences and cellular consequences. Cell Signal 2002, 14:477-492

4. Sade-Feldman M, Kanterman J, Ish-Shalom E, Elnekave M, Horwitz E, Baniyash M: Tumor necrosis factor- $\alpha$ blocks differentiation and enhances suppressive activity of immature myeloid cells during chronic inflammation. Immunity 2013, 38:541-554

5. Yeung F, Hoberg JE, Ramsey CS, Keller MD, Jones DR, Frye RA, Mayo MW: Modulation of NF-[kappa]B-dependent transcription and cell survival by the SIRT1 deacetylase. EMBO J 2004, 23:2369-2380

6. Zhang J, Lee S-M, Shannon S, Gao B, Chen W, Chen A, Divekar R, McBurney MW, Braley-Mullen H, Zaghouani H, Fang D: The type III histone deacetylase Sirt1 is essential for maintenance of T cell tolerance in mice. J Clin Invest 2009, 119:3048-3058

7. Sequeira J, Boily G, Bazinet S, Saliba S, He X, Jardine K, Kennedy C Staines W, Rousseaux C, Mueller R, McBurney MW: Sirt1-null mice develop an autoimmune-like condition. Exp Cell Res 2008, 314: 3069-3074

8. Singh NP, Hegde VL, Hofseth LJ, Nagarkatti M, Nagarkatti P. Resveratrol (trans-3,5,4'-trihydroxystilbene) ameliorates experimental allergic encephalomyelitis, primarily via induction of apoptosis in $\mathrm{T}$ cells involving activation of aryl hydrocarbon receptor and estrogen receptor. Mol Pharmacol 2007, 72:1508-1521

9. Milne JC, Lambert PD, Schenk S, Carney DP, Smith JJ, Gagne DJ, Jin L, Boss O, Perni RB, Vu CB, Bemis JE, Xie R, Disch JS, Ng PY, Nunes JJ, Lynch AV, Yang H, Galonek H, Israelian K, Choy W, Iffland A, Lavu S, Medvedik O, Sinclair DA, Olefsky JM, Jirousek MR, Elliott PJ, Westphal CH: Small molecule activators of SIRT1 as therapeutics for the treatment of type 2 diabetes. Nature 2007, 450:712-716

10. Gardner PJ, Joshi L, Lee RWJ, Dick AD, Adamson P, Calder VL: SIRT1 activation protects against autoimmune $\mathrm{T}$ cell-driven retinal disease in mice via inhibition of IL-2/Stat5 signaling. J Autoimmun 2013, 42:117-129 
11. Sauve AA, Wolberger C, Schramm VL, Boeke JD: The biochemistry of sirtuins. Annual Review of Biochemistry. Palo Alto, Annual Reviews, 2006, pp 435-465

12. Huang H, Tindall DJ: Dynamic FoxO transcription factors. J Cell Sci 2007, 120:2479-2487

13. Dai H, Kustigian L, Carney D, Case A, Considine T, Hubbard BP, Perni RB, Riera TV, Szczepankiewicz B, Vlasuk GP, Stein RL: SIRT1 activation by small molecules. J Biol Chem 2010, 285:32695-32703

14. Dvir-Ginzberg M, Gagarina V, Lee EJ, Booth R, Gabay O, Hall DJ: Tumor necrosis factor $\alpha$-mediated cleavage and inactivation of SirT1 in human osteoarthritic chondrocytes. Arthritis Rheum 2011, 63:2363-2373

15. Copland DA, Wertheim MS, Armitage WJ, Nicholson LB, Raveney BJE, Dick AD: The clinical time-course of experimental autoimmune uveoretinitis using topical endoscopic fundal imaging with histologic and cellular infiltrate correlation. Invest Ophthalmol Vis Sci 2008, 49:5458-5465

16. Gegg ME, Harry R, Hankey D, Zambarakji H, Pryce G, Baker D, Adamson P, Calder V, Greenwood J: Suppression of autoimmune retinal disease by lovastatin does not require Th2 cytokine induction. J Immunol 2005, 174:2327-2335

17. Edling AE, Gomes D, Weeden T, Dzuris J, Stefano J, Pan C, Williams J, Kaplan J, Perricone MA: Immunosuppressive activity of a novel peptide analog of alpha-melanocyte stimulating hormone $(\alpha-$ MSH) in experimental autoimmune uveitis. J Neuroimmunol 2011, 236:1-9

18. Dick AD, McMenamin PG, Körner H, Scallon BJ, Ghrayeb J, Forrester JV, Sedgwick JD: Inhibition of tumor necrosis factor activity minimizes target organ damage in experimental autoimmune uveoretinitis despite quantitatively normal activated $\mathrm{T}$ cell traffic to the retina. Eur J Immunol 1996, 26:1018-1025

19. Dick AD, Duncan L, Hale G, Waldmann H, Isaacs J: Neutralizing TNF-alpha activity modulates T-cell phenotype and function in experimental autoimmune uveoretinitis. J Autoimmun 1998, 11: $255-264$

20. Robertson M, Liversidge J, Forrester JV, Dick AD: Neutralizing tumor necrosis factor- $\alpha$ activity suppresses activation of infiltrating macrophages in experimental autoimmune uveoretinitis. Invest Ophthalmol Vis Sci 2003, 44:3034-3041

21. Ramos-Casals M, Brito-Zerón P, Soto M-J, Cuadrado M-J, Khamashta MA: Autoimmune diseases induced by TNF-targeted therapies. Best Pract Res Clin Rheumatol 2008, 22:847-861

22. Dick AD, Forrester JV, Liversidge J, Cope AP: The role of tumour necrosis factor (TNF- $\alpha$ ) in experimental autoimmune uveoretinitis (EAU). Prog Retin Eye Res 2004, 23:617-637

23. Atan D, Heissigerova J, Kuffová L, Hogan A, Kilmartin DJ, Forrester JV, Bidwell JL, Dick AD, Churchill AJ: Tumor necrosis factor polymorphisms associated with tumor necrosis factor production influence the risk of idiopathic intermediate uveitis. Mol Vis 2013, 19: $184-195$

24. Joseph A, Raj D, Dua HS, Powell PT, Lanyon PC, Powell RJ: Infliximab in the treatment of refractory posterior uveitis. Ophthalmology 2003, 110:1449-1453

25. Smith JR, Hart PH, Coster DJ, Williams KA: Mice deficient in tumor necrosis factor receptors $\mathrm{p} 55$ and $\mathrm{p} 75$, interleukin-4, or inducible nitric oxide synthase are susceptible to endotoxin-induced uveitis. Invest Ophthalmol Vis Sci 1998, 39:658-661

26. Koizumi K, Poulaki V, Doehmen S, Welsandt G, Radetzky S, Lappas A, Kociok N, Kirchhof B, Joussen AM: Contribution of TNF- $\alpha$ to leukocyte adhesion, vascular leakage, and apoptotic cell death in endotoxin-induced uveitis in vivo. Invest Ophthalmol Vis Sci 2003, 44:2184-2191

27. Yadav UC, Shoeb M, Srivastava SK, Ramana KV: Aldose reductase deficiency protects from autoimmune- and endotoxin-induced uveitis in mice. Invest Ophthalmol Vis Sci 2011, 52:8076-8085
28. Kasner L, Chan CC, Whitcup SM, Gery I: The paradoxical effect of tumor necrosis factor alpha (TNF-alpha) in endotoxin-induced uveitis. Invest Ophthalmol Vis Sci 1993, 34:2911-2917

29. Rosenbaum J, Han Y, Park JM, Kennedy M, Planck S: Tumor necrosis factor-alpha is not essential in endotoxin induced eye inflammation: studies in cytokine receptor deficient mice. J Rheumatol 1998, 25:2408

30. Agarwal R, Silver P, Caspi R: Rodent Models of Experimental Autoimmune Uveitis. Autoimmunity: Methods and Protocols. New York City, NY, Humana Press (Springerlink), 2012, pp 443-469

31. Kerr EC, Raveney BJE, Copland DA, Dick AD, Nicholson LB: Analysis of retinal cellular infiltrate in experimental autoimmune uveoretinitis reveals multiple regulatory cell populations. J Autoimmun 2008, 31:354-361

32. Xu H, Manivannan A, Liversidge J, Sharp PF, Forrester JV, Crane IJ: Involvement of CD44 in leukocyte trafficking at the blood-retinal barrier. J Leukoc Biol 2002, 72:1133-1141

33. Zhang Z, Wu X, Duan J, Hinrichs D, Wegmann K, Zhang GL, Hall M, Rosenbaum JT: Low dose rapamycin exacerbates autoimmune experimental uveitis. PLoS One 2012, 7:e36589

34. Luger D, Silver PB, Tang J, Cua D, Chen Z, Iwakura Y, Bowman EP, Sgambellone NM, Chan C-C, Caspi RR: Either a Th17 or a Th1 effector response can drive autoimmunity: conditions of disease induction affect dominant effector category. J Exp Med 2008, 205:799-810

35. Hoey S, Grabowski PS, Ralston SH, Forrester JV, Liversidge J: Nitric oxide accelerates the onset and increases the severity of experimental autoimmune uveoretinitis through an IFN-gamma-dependent mechanism. J Immunol 1997, 159:5132-5142

36. Anderson MR, Tary-Lehmann M: Staphylococcal enterotoxin-Binduced lethal shock in mice is T-cell-dependent, but disease susceptibility is defined by the non-T-cell compartment. Clin Immunol 2001, 98:85-94

37. Allie N, Grivennikov SI, Keeton R, Hsu N-J, Bourigault M-L, Court N, Fremond C, Yeremeev V, Shebzukhov Y, Ryffel B, Nedospasov SA, Quesniaux VFJ, Jacobs M: Prominent role for T cell-derived tumour necrosis factor for sustained control of Mycobacterium tuberculosis infection. Sci Rep 2013, 3:1-14

38. Xu L, Yoon H, Zhao MQ, Liu J, Ramana CV, Enelow RI: Cutting Edge: pulmonary immunopathology mediated by antigen-specific expression of TNF- $\alpha$ by antiviral CD8 + T cells. J Immunol 2004, $173: 721-725$

39. Rossol M, Meusch U, Pierer M, Kaltenhäuser S, Häntzschel H, Hauschildt S, Wagner U: Interaction between transmembrane TNF and TNFR $1 / 2$ mediates the activation of monocytes by contact with $\mathrm{T}$ cells. J Immunol 2007, 179:4239-4248

40. LeHoang P: The gold standard of noninfectious uveitis: corticosteroids. Dev Ophthalmol 2012, 51:7-28

41. Guo C, Chu X, Shi Y, He W, Li L, Wang L, Wang Y, Peng J, Hou M: Correction of Th1-dominant cytokine profiles by high-dose dexamethasone in patients with chronic idiopathic thrombocytopenic purpura. J Clin Immunol 2007, 27:557-562

42. Pichyangkul S, Schick D, Schober W, Dixon G, Khan A: Increased expression of adhesive proteins on leukocytes by TNF alpha. Exp Hematol 1988, 16:588-593

43. Yossuck P, Yan Y, Tadesse M, Higgins RD: Dexamethasone alters TNF- $\alpha$ expression in retinopathy. Mol Genet Metab 2001, 72: $164-167$

44. Oppenheimer H, Gabay O, Meir H, Haze A, Kandel L, Liebergall M, Gagarina V, Lee EJ, Dvir-Ginzberg M: 75-kd Sirtuin 1 blocks tumor necrosis factor $\alpha$-mediated apoptosis in human osteoarthritic chondrocytes. Arthritis Rheum 2012, 64:718-728

45. Li L, Wang L, Li L, Wang Z, Ho Y, McDonald T, Holyoake TL, Chen W, Bhatia R: Activation of p53 by SIRT1 inhibition enhances elimination of CML leukemia stem cells in combination with imatinib. Cancer Cell 2012, 21:266-281 